\title{
PROSPECTIVE TEACHERS' COPING WITH MATHEMATICAL ALGORITHMS IN A FLIPPED CLASS SETTING
}

\author{
Ilana Lavy ${ }^{1}, \&$ Atara Shriki ${ }^{2}$ \\ ${ }^{1}$ Information Systems Dep., Yezreel Valley College (Israel) \\ ${ }^{2}$ Science and Mathematics Education Faculty, Kibbutzim College (Israel)
}

\begin{abstract}
The implementation of the flipped-class learning method has been increasing during the last several years in the education system. The underlying idea of the flipped-class method is that learning materials that students can study and manage by themselves are handed to their responsibility. This allows teachers to focus the classroom meetings on educational activities such as discussions on difficulties the students tackled during their independent learning, and to adjust the teaching to students' personal needs. As a result, students develop self-regulated learning skills and deepen their knowledge of the subject matter.

The aim of the current research was to explore the effects of flipped-class learning on changes in prospective teachers' perceived sense of mathematical self-efficacy as a result of their independent coping with mathematical patterns and algorithms as part of a one-semester course. Successes and failures in performing mathematical tasks affect learners' perceived mathematical self-efficacy, which refers to the individuals' perception of their ability to cope successfully with mathematical tasks.

Once in two weeks, a lesson about mathematical patterns of various types (e.g., arithmetic series) or mathematical algorithms (for example, Euclid's algorithm) was uploaded to the course site. The prospective teachers were asked to read the learning materials, pose relevant mathematical problems and answer them. The face-to-face class meetings were dedicated to discussing students' difficulties, implementation of the learned materials through engaging the problems that were posed by the students and providing personalized assistance to students that encountered difficulties during their self-learning. The prospective teachers who attended the course were in their third year (out of four) of studies towards B.Ed. degree and were specializing in teaching elementary school mathematics. As it was their first experience in learning in this format, we were interested in exploring emotional aspects of their engagement with the course contents, and their sense of self-efficacy.

The research tools included transcriptions of class discussions and prospective teachers' reflective journals in which they documented their experience and reflected upon their feelings and the insights they gained as a result of experiencing learning mathematical contents in a flipped class setting. Using content analysis methods, we looked for evidence of the impact of flipped class learning on the prospective teachers' perceived mathematical self-efficacy.
\end{abstract}

Keywords: Flipped class, self-efficacy, prospective teachers, patterns, algorithms.

\section{Introduction}

The implementation of the flipped-class learning model has been increasing during the last several years in the education system in general and in mathematics education in particular. The underlying idea of the flipped- class method is that the topics students can learn and handle by themselves are transferred to their responsibility. This frees the classroom meetings to other educational activities, and they are utilized to discussions on difficulties the students tackled during their self-learning, and to individual assistance to the students in need (Love, Hodge, Grandgenett, \& Swift, 2014).

As part of the prospective mathematics teachers (PMTs) training to become mathematics teachers, it is important to expose them to a variety of teaching/learning methods. We believe that self-experience raises the odds that the PMTs will consider adopting such methods in their future classes. These odds are also influenced by PMT's self-efficacy (Bandura, 1982). Self-efficacy refers to the manner in which a person perceives his ability to complete a particular task.

The flipped-class method was implemented in a third-year course in which the PMTs were engaged with mathematical patterns and algorithms. These PMTs were specializing in teaching 
elementary school mathematics. As it was their first experience in learning in this format, we decided to explore affective aspects of this engagement focusing on aspects relating to self-efficacy. In this study, we examined a variety of aspects of students' experience in learning mathematics in the flipped class, and in this paper, we will address the issue of mathematical self-efficacy.

\section{Brief theoretical background}

\subsection{Flipped-class learning method}

The idea behind the flipped-class method is that the learning materials are given to the students for self-learning at home, while the lessons in the class are devoted to discussions, to implementation of the learning materials and to the provision of assistance for the students in need. Thus, the responsibility of learning is now passed to the learners. They can set their own learning pace and monitor their learning process. Teachers are encouraged to promote collaborations among learners, develop their independent learner skills, help them understand the issues they have dealt with independently, and challenge them with exploration tasks. It was found that this learning method has the potential to motivate learners to take an active part in their learning process (Love, Hodge, Grandgenett \& Swift, 2014). As regards to the learning of mathematics, a review of the research literature conducted by Lai and Hwang (2016) shows that learning using the flipped-class method enables active learning, develops the learner's ability to set educational goals, fosters high-order mathematical thinking and contributes to the strengthening of the students' mathematical self-efficacy. However, students with low levels of independent learning skills do not benefit from flipped class learning and find it difficult to integrate into classes.

\subsection{A sense of mathematical self-efficacy}

Bandura (1977a, 1997) defined perceived self-efficacy as personal judgments of one's capabilities to plan, arrange and carry out actions to achieve designated goals. The level of self-efficacy refers to its dependence on the difficulty of the performed task, such as trying to solve a mathematically complex problem; to the transferability of self-efficacy beliefs across activities, such as from algebra to geometry; strength of perceived efficacy is measured by the amount of one's certainty about performing a given task.

Perceived mathematical self-efficacy refers to the way a person perceives his ability to complete a particular task (Bandura, 1982). Experiencing successes have been found to reinforce perceived self-efficacy while experiencing failures weaken it and make it impossible to cope with similar tasks (Bandura, 1994). Bandura (ibid) referred to the main sources of influence of one's perceived self-efficacy saying that they include (1) mastery experiences; (2) seeing people similar to oneself manage task demands successfully; (3) social persuasion that one has the capabilities to succeed in given activities; and (4) inferences from somatic and emotional states indicative of personal strengths and vulnerabilities. Perceived mathematical self-efficacy refers to an individual's perception of his ability to cope successfully with a mathematical task. Perceived mathematical self-efficacy has a bigger impact on mathematical achievements than to variables such as mathematical anxiety, socio-economical background, and gender (OECD, 2013).

\section{The study}

\subsection{The study participants}

26 students in their third year of B.Ed. studies at a College of Education located in the northern part of our country, specializing in teaching mathematics at elementary school participated in the study. Students studied in a flipped class format as part of a semester course dealing with various mathematical patterns (for example, arithmetic sequence) and mathematical algorithms (for example, Euclid's algorithm). For all students, this was their first experience in learning mathematical content using the flipped class method.

\subsection{The context of the study}

The students attended a one-semester course dealing with mathematical patterns and algorithms, in which they experienced flipped-class learning. Once every two weeks, a new chapter was uploaded to the course website. To help students monitor their self-learning, they were instructed to pose questions relating to the learned materials and answer them. Every third week a plenary session was held for responding and discussing students' difficulties and the challenges they encountered during their individual work. As part of the classroom discussions, the students were given the opportunity to receive feedback from the lecturer on the questions they posed and their solutions, and to be exposed to questions posed by their classmates, in order to deepen insights regarding the contribution of posing questions as a means of managing independent learning. In the final examination, students were asked to analyze and 
apply unfamiliar patterns and algorithms.

\subsection{The aim of the study and derived question}

The aim of the study was to examine cognitive as well as emotional aspects, relating to the students' experience in learning patterns and mathematical algorithms in the format of the flipped class, as perceived by them.

Due to space limitations, we will address one of the research questions:

How do prospective teachers perceive the effect of studying mathematics in a format of flipped class learning on their sense of mathematical self-efficacy?

\subsection{Tools for data collection and analysis}

The data gathered included a reflective journal in which the students documented their learning process. The journal also included the questions they posed and the answers to these questions. The use of a reflective journal as part of teacher training has advantages both in terms of strengthening the connection between the lecturer and the students and in terms of empowering the learning process. In addition, the research data included recordings of class meetings and the students' answers to the final test questions.

The information obtained from the reflective journals and the transcripts of the class sessions was analyzed using content analysis (Neuendorf, 2002). The results of the content analysis were also examined in relation to the grades that were obtained in the final test of the course.

\section{Results and discussion}

\subsection{Prospective teachers' perceptions as regards to the effect of learning in a format of flipped class with relation to their sense of mathematical self-efficacy}

In the first two weeks of the course, most students (22 out of 26) expressed reservations about the flipped class method and wrote in their reflective journals: "I don't have the tools to do a lecturer job. In the classroom, teachers teach math and explain in real time the things I don't understand. That's how I am able to understand". "Not every new method should be tried on us. This expectation that we will only be able to understand the various stages of these algorithms and formulas is ambitious and a little exaggerated in my opinion".

"The [flipped class] method does not contribute to understanding these issues, nor is it clear how posing questions will help me understand. We are dealing here with mathematical patterns and not with stories".

By the mid-semester, the students' reactions were changed. In their reflective journals, they wrote: "At first, I felt frustrated in lessons because I felt the questions I posed were common and trivial, and I didn't know if I really understood the algorithm. I posed questions because those were the guidelines. I didn't even see the connection between the questions and my learning".

"When I heard the questions posed by my classmates, I realized that if they were able to come with such results, so could I. I also learned a lot from your [the lecturer] analysis of the relationship between the questions and the stages of the algorithm".

"Despite the difficulties I encountered, I didn't give up, which gave me a good feeling that I could learn on my own. The truth is, that is was our first experience with this way of learning and it took us time to adjust to it. I know I was really upset at first and even angry, but with the first success came the joy, which gave me the motivation to continue".

In the final reflection, students wrote:

"I saw that my questions were really good, so I started attending the class discussions. It greatly enhanced my confidence, because I realized that I was able to succeed in this learning method".

"I think that only after you get positive feedback on what you do, only then do you get that urge to keep going, and that is how your self-confidence develops".

"It's kind of weird because I've never thought that self-confidence strengthens when you compare your achievements to others, even though you are actually learning from them".

Not all students experienced the feelings described above. Low achievers wrote reflections like: "I need the lecturer to explain to me. Can't study alone"; "flipped classroom learning doesn't suit me. point." "I gave up and did not come ready for class discussions". "I couldn't think of any questions to help me understand the algorithms, and it just made me helpless". "Not every teaching method is suitable for everyone ... I saw that others were successful, and I couldn't understand, and it was really frustrating not to understand this course. The fact that others succeeded, and I did not, made me feel even worse".

Analysis of the students' reflections revealed references to three main aspects: feelings (marked by an underline), knowledge (marked by bold letters), and sense of mathematical self-efficacy (SMSE) 
(marked by italic style).

At the beginning of the process, there was a sense of general frustration, expressed by most students, stemming from their difficulty to pose significant questions that their answers will help them understand the algorithm at hand., which would help them understand the algorithm at hand. The classroom discussions in which successful experiences were presented and discussed led to a change in the average and high achievers that if their peers are capable, then they also can. Moreover, in the classroom discussions, a standard was set for the posed questions, which increased as a result of covert competition created among the students to show that they can do better than their peers. These results are in line with Zimmerman (2000) who found a strong connection between self-efficacy and motivation to learn.

The number of active participants in the discussions increased from week to week and the discussions dealt with topics that they work out on became more and more interesting and meaningful. Viewing peers' outcomes motivated the students to invest efforts and pose questions that would help them understand the algorithms. These findings are in line with Bandura (1994), who found that successes were found to reinforce students' sense of mathematical self-ability while failures result in a sense of frustration and helplessness, and a decline in mathematical self-ability to avoid coping with course content.

The flipped class method consists of independent learning and classroom sessions. Observing the obtained results reveal that both components affected the students' mathematical self-efficacy. However, for the low achievers, there should be additional actions to be taken under consideration in order to help them develop independent learning skills so that they will be able to experience successes while learning in a flipped class method. Bandura (1994) referred to the main sources of influence of one's perceived self-efficacy saying that they include (1) mastery experiences; (2) seeing people similar to oneself manage task demands successfully; (3) social persuasion that one has the capabilities to succeed in given activities; and (4) inferences from somatic and emotional states indicative of personal strengths and vulnerabilities. If we look at the process the students had gone through during the course, we can find references to the four sources influencing one's perceived self-efficacy. At the beginning of the course, the students were asked to cope with the understanding of mathematical algorithms in a setting that was new to them. The difficulties they experienced aroused in them negative feelings of frustration and experiences of unsuccessfulness which in turn decreased their mathematical self-efficacy. The class discussions exposed them to the successes of some of their peers, which inspired them to invest more effort, and try to be equally and even more successful. The classroom discussions and the encouragement of the classroom teacher provided them also with social recognition that they can succeed. However, this process was found to be effective for the average and high achiever students but did not work well for the low achiever students. As Bandura (1994) said that it is not the emotional reactions that are important rather how it is perceived and interpreted. People who have a high sense of efficacy are likely to view their state of affective arousal as an energizing facilitator of performance, whereas those who are affected by self- doubts regard their arousal as a debilitator. Since low achievers have already low mathematical self-efficacy as a result of prior low achievements, adding to the challenge of new learning methods in addition to the difficulty of coping with a mathematical task did not contribute to improving their perceive mathematical self-efficacy.

In light of the positive correlation between mathematics achievements and self-efficacy (OECD, 2013), the experience described above seems to have reinforced this feeling among those who had a high sense of mathematical self-efficacy in the first place, while the experience was weakened by others. Therefore, the research findings raise questions about how to support the learning of low-achievement students in mathematics required to study in the flipped classroom.

\section{Concluding remarks}

The incorporation of new teaching methods into the educational system is important and valuable. However, careful consideration should be given to the question of whether a method is suitable for all learners or should it be modified to fit different populations of learners as emerging from the present study. This is especially relevant when planning the new student generations for the next decade. The OECD (2019) released a document in which several principles to shape future learning are recommended. One of these principles refers to personalization which means customizing content, products, and services to the specific needs and desires of a student to increase the added value she/he receives during the learning process. This trend is being intensified due to the ability of technology to identify and meet the specific needs of each individual through a growing range of products and services. The strengths of each method should be examined as well as its weaknesses, investing plenty of effort in looking for ways to minimize its weaknesses. 
This research should be followed by studies that will address the following issues:

- What is the unique contribution of each of the flipped class method components to the cultivation of high-order mathematical thinking?

- What is the connection between the initial level of mathematical self-efficacy and the rise/fall of that feeling in a flipped classroom learning setting?

- How can we support the learning of low-achieving math students required to study in the flipped classroom?

\section{References}

Bandura, A. (1977a). Self-efficacy: Toward a unifying theory of behavior change. Psychological Review, $84,191-215$.

Bandura, A. (1982). Self-efficacy mechanism in human agency. American Psychologist, 37(2), 122-147.

Bandura, A. (1994). Self-efficacy, in V. Ramachaudran (ed.), Encyclopedia of human behavior, Vol. 4 (pp. 71-81). New York, NY: Academic Press.

Bandura, A. (1997). Self-efficacy: The exercise of control. New York: Freeman.

Lai, C-L., \& Hwang, G-J. (2016). A self-regulated flipped-classroom approach to improving students' learning performance in a mathematics course. Computers and Education, 100, 126-140.

Love, B., Hodge, A., Grandgenett, N., \& Swift, A.W. (2014). Student learning and perceptions in a flipped linear algebra course. International Journal of Mathematical Education in Science \& Technology, 45(3), 317-324.

Neuendorf, K. A. (2002). The Content Analysis Guidebook. Thousand Oaks, CA: Sage Publications.

O'Connell, T. S., \& Dyment, J. E. (2011). The case of reflective journals: Is the jury still out? Reflective Practice, 12, 47-59.

OECD (2013). PISA 2012 assessment and analytical framework: Mathematics, reading, science, problem-solving and financial literacy. OECD Publishing. Available at: https://www.oecd.org/pisa/pisaproducts/PISA\%202012\%20framework\%20e-book_final.pdf

$\begin{array}{llllll}\text { OECD (2019). } & \text { Future of } & & & \\ \end{array}$ https://www.oecd.org/education/2030project/contact/OECD_Learning_Compass_2030_Concept_ Note_Series.pdf

Zimmerman, B.J. (2000). Self-Efficacy: An Essential Motive to Learn. Contemporary Educational Psychology 25, 82-91. 